\title{
TOXOPLASMOSE DO SISTEMA NERVOSO CENTRAL. CORRELAÇÃO CLINICOPATOLÓGICA EM 7 CASOS DE AUTÓPSIA
}

\author{
Aristides Cheto de Queiroz, Cristlana Maria Pacheco Costa Nascimento \\ e Eduardo A. Gonçalves Ramos
}

\begin{abstract}
$O$ trabalho mostra o estudo anatomopatológico de 7 casos de Toxoplasmose do sistema nervoso central, com diagnósticos feitos exclusivamente em autópsias. $O$ trabalho chama atenção para a dificuldade de diagnóstico clínico desta entidade e mostra dois casos de apresentaçâo mais rara com manifestações clínicas e anatomopatológicas que simulam abscessos cerebrais. O comprometimento do plexo coróide, freqüente neste material, fortalece a idéia de que esta estrutura desempenha papel importante na disseminação da doença no sistema nervoso central.
\end{abstract}

Palavras chaves: Toxoplasma gondii. Toxoplasmose. Encefalite por Toxoplasma. Correlação clinicopatológica.

A toxoplasmose è uma infecção amplamente distribuida nas várias regiões do globo terrestrel 236782021 . Em nosso meio tem sido mostrada uma prevalência sorológica positiva, que varia entre $36,57 \%$ e $61 \% 131419$. Provavelmente, devido à baixa patogenicidade do parasito, é pequeno o número de indivíduos adultos infectados que apresentam manifestação da doença. A doença aparece freqüentemente em pacientes debilitados e imunodeprimidos 101112 , sendo o SNC o local de maior repercussão. Pela sua apresentação clínica proteiforme, constitui-se uma condição que não raramente deixa de ser diagnosticada. Esta afirmativa é válida principalmente para os casos de comprometimento cerebral, onde na maioria das vezes o diagnóstico é feito na autópsia ${ }^{11} 16$.

O estudo de casos diagnosticados em autópsia pode trazer contribuições importantes para o aprimoramento da suspeita e de diagnóstico clínico da doença.

O presente trabalho mostra a análise de 7 casos de toxoplasmose-doença diagnosticados na autópsia, onde são feitos estudos da correlação clínico-patológica.

\section{MATERIAL E MÉTODOS}

Foram estudados 6 casos de toxoplasmose existentes no arquivo do Departamento de Anatomia Patológica do Hospital Professor Edgard Santos da Universidade Federal da Bahia, no periodo de 1970 a 1986, em um total de 2.449 autópsias e 1 caso de

Trabalho realizado no Serviço de Anatomia Patológica do Hospital Prof. Edgard Santos - UFBA e Hospital Couto Maia, Salvador-Bahia. toxoplasmose no arquivo do Hospital Couto Maia em 1983. Todos os casos foram submetidos a autópsias completas com estudo macroscópico e microscópico de todos os órgãos. Em todos os casos, foi feita uma revisão dos prontuários clínicos e protocolos de autópsia.

Os encéfalos foram examinados 20 dias após fixação em formol a $10 \%$ em suspensão. Os fragmentos retirados para estudo histológico foram processados de maneira habitual para inclusão em parafina. As secções cortadas a espessura de $5 \mu \mathrm{m}$ foram coradas pela hematoxilina e eosina, PAS e Grocott. As lâminas assim foram então reexaminadas.

\section{RESULTADOS}

Todos os casos aqui apresentados tiveram o diagnóstico de toxoplasmose feito exclusivamente com o estudo da necrópsia. Os principais dados clínicos e anatomopatológicos estão expressos nas Tabelas 1 e 2. Chamam atenção as manifestações da doença no sistema nervoso central, presentes em todos os casos. Do ponto de vista anatomopatológico existia em todos eles um quadro de meningoencefalite multifocal, de intensidade variável de caso para caso. As lesões de maior gravidade estavam representadas por intensa destruição tecidual, com necrose, reação celular mononuclear, com predominância de linfócitos, plasmócitos e reação macrofágica, sendo muito freqüente o encontro de parasitos intracelulares livres no tecido e mais raramente sob a forma de pseudocistos (Fig. 1). Nas lesões de menor gravidade observou-se reação inflamatória com predominância de macrófagos constituindo verdadeiros granulomas, ao lado de plasmócitos e linfócitos em menor intensidade. Estas eram lesões multifocais, com pouco parasitismo celu- 
Queiroz AC, Nascimento CMPC, Ramos EAG. Toxoplasmose do sistema nervoso central. Correlação clinicopatológica em 7 casos de autópsia. Revista da Sociedade Brasileira de Medicina Tropical 20: 175-180, Jul-Set, 1987.

Tabela 1 - Toxoplasmose do sistema nervoso central. Dados clinicopatológicos de 7 casos de autópsia.

\begin{tabular}{|c|c|c|c|c|}
\hline Idade & Sexo & Doença básica & $\begin{array}{l}\text { Tipo da lesão no } \\
\text { sistema nervoso }\end{array}$ & Outros órgãos \\
\hline 42 & $\mathbf{M}$ & LMA & Encefalite multifocal & $-0-$ \\
\hline $8 \mathrm{~m}$ & $\mathbf{F}$ & $\begin{array}{l}\text { Meningite } \\
\text { purulenta }\end{array}$ & Encefalite focal $p /$ Toxoplasma & $-0-$ \\
\hline 42 & $\mathbf{M}$ & $\begin{array}{l}\text { Encefalite } \\
\text { p/toxoplasmose }\end{array}$ & $\begin{array}{l}\text { Meningoencefalite }+ \\
\text { forma de abscesso }\end{array}$ & Coração \\
\hline 50 & $\mathbf{M}$ & Cardiopatia & Meningoencefalite multifocal & Coração e figado \\
\hline 27 & $\mathbf{F}$ & LLA & Meningoencefalite multifocal & $-0-$ \\
\hline 27 & $\mathbf{M}$ & $\begin{array}{l}\text { Encefalite } p / \\
\text { toxoplasmose }\end{array}$ & $\begin{array}{l}\text { Meningoencefalite }+ \\
\text { forma de abscesso }\end{array}$ & Coração \\
\hline 35 & F & D. Hodgkin & Encefalite necrotizante & Pulmão e figado \\
\hline
\end{tabular}

LMA = Leucemia mielóide aguda

LLA = Leucemia linfóide aguda

Tabela 2 - Toxoplasmose do sistema nervoso central. Principais dados clínicos do envolvimento neurologico. Estudo de 7 casos de autópsia.

\begin{tabular}{|c|c|c|c|}
\hline Idade & Sexo & $\begin{array}{l}\text { Tipo de lesão ana- } \\
\text { tomopatológica } \\
\text { no SNC }\end{array}$ & Manifestações neurológicas \\
\hline 42 & $\overline{\mathbf{M}}$ & $\begin{array}{l}\text { Encefalite multi- } \\
\text { focal necrotizante }\end{array}$ & $\begin{array}{l}\text { Tonturas, insônia, dormência nas } \\
\text { mãos }\end{array}$ \\
\hline $8 \mathrm{~m}$ & F & $\begin{array}{l}\text { Encefalite focal } \\
\text { por Toxoplasma }\end{array}$ & $\begin{array}{l}\text { Tremores, torpor, reflexos de preensão } \\
\text { abolidos }\end{array}$ \\
\hline 42 & $\mathbf{M}$ & $\begin{array}{l}\text { Meningoencefalite } \\
+ \text { forma de abscesso }\end{array}$ & Hemiplegia à esquerda \\
\hline 50 & $\mathbf{M}$ & $\begin{array}{l}\text { Meningoencefalite } \\
\text { multifocal }\end{array}$ & $\begin{array}{l}\text { Sinais de irritação meningea, } \\
\text { convulsões }\end{array}$ \\
\hline 27 & $F$ & $\begin{array}{l}\text { Meningoencefalite } \\
\text { multifocal }\end{array}$ & $\begin{array}{l}\text { Cefaléia, tonturas, dormência nos pés } \\
\text { e mãos, desvio de comissura labial } \\
\text { p/direita }\end{array}$ \\
\hline 27 & $\mathbf{M}$ & $\begin{array}{l}\text { Meningoencefalite } \\
\text { + forma de } \\
\text { abscesso }\end{array}$ & $\begin{array}{l}\text { Tonturas, dormència nas pernas, } \\
\text { rigidez de nuca, coma c/postura de } \\
\text { descerebração }\end{array}$ \\
\hline 35 & F & $\begin{array}{l}\text { Encefalite } \\
\text { necrotizante }\end{array}$ & $\begin{array}{l}\text { Cefaléia, sonolência e lentidão de } \\
\text { pensamento }\end{array}$ \\
\hline
\end{tabular}

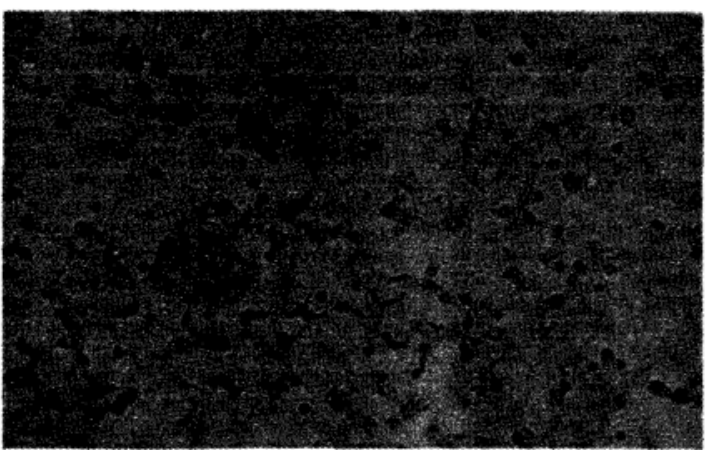

Fig. 1 - A figura ilustra o grande parasitismo tecidual em um dos casos de maior gravidade da toxoplasmose doença no SNC. Hematoxilina e eosina. $\times 400$. lar ou tecidual, sendo entretanto mais comum encontrar os pseudocistos parasitários nas proximidades. Um aspecto histopatológico freqüente foi a presença de reação inflamatória perivascular com linfócitos e plasmócitos encontrada nos casos de lesão tecidual de maior intensidade (Figs. 2 e 3 ).

O estudo do plexo coróide foi feito em 4 dos 7 casos examinados. Nestes casos foi constatada a presença de lesão inflamatória no eixo das vilosidades, com formação granulomatosa ou sob a forma de infiltrado linfocitário, mas na ausência de elementos parasitários (Fig. 4).

Independente da intesidade da lesão anatomopatológica houve, em todos os casos, uma tradução clínica de doença no SNC, com manifestações neuro- 
Queiroz AC, Nascimento CMPC, Ramos EAG. Toxoplasmose do sistema nervoso central. Correlação clinicopatológica em 7 casos de autópsia. Revista da Sociedade Brasileira de Medicina Tropical 20: 175-180, Jul-Set, 1987.

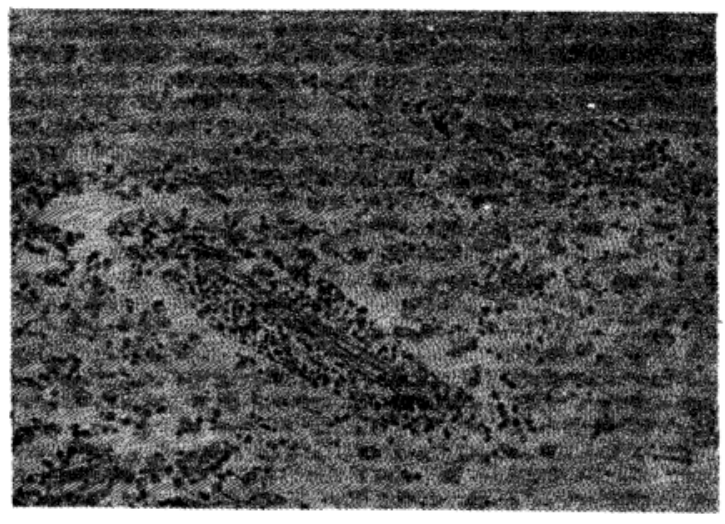

Fig.2 - Seção de cérebro em um caso de maior intensidade de lesão, com desintegração tecidual, grande reação celular perivascular e reação macrofágica. Hematoxilina e eosina. $x 200$.

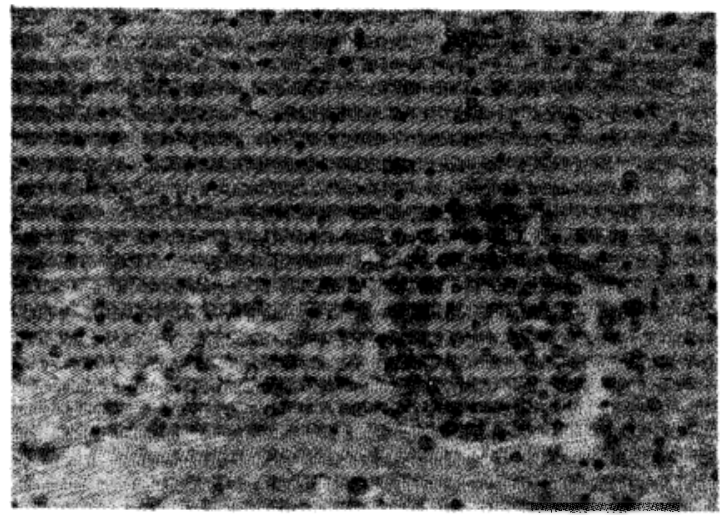

Fig. 3 - Lesão inflamatória mononuclear perivascular da encefalite por toxoplasma. Observaro parasitismo tecidual. Hematoxilina e eosina. $x 400$.

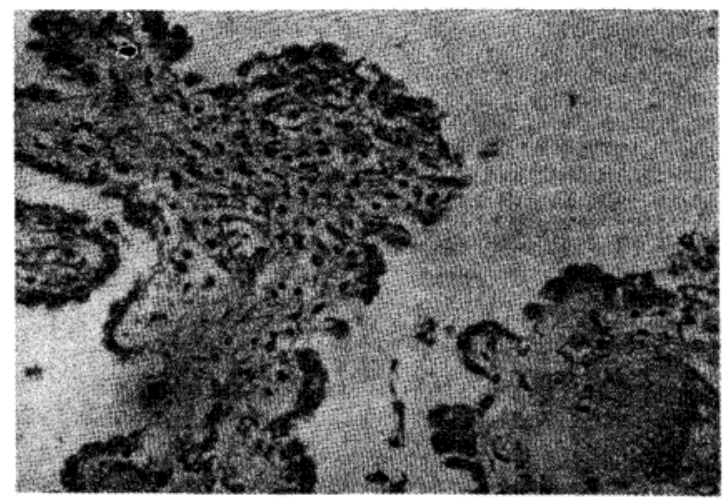

Fig. 4 - Lesão inflamatória granulomatosa do eixo conjuntivo do plexo coróide em um caso de toxoplasmose. Observar a destruição do epitélio de revestimento. Hematoxilina e eosina. $\times 200$. lógicas variáveis e inespecíficas. Em dois dos casos a apresentação foi menos comum ainda, confundida do ponto de vista anatomopatológico como abscesso cerebral (Figs. 5 e 6). Estes tiveram apresentação clínica com sinais de doença localizada no SNC, independente de apresentarem também o quadro anatomopatológico de meningoencefalite multifocal. A causa de morte, nestes casos, foi atribuída diretamente à doença toxoplasmose, tendo em vista a existência da forma disseminada, envolvendo outros órgãos, e da forma grave de envolvimento cerebral. Nos demais a causa de morte esteve ligada a complicação das doenças básicas preexistentes, sempre de natureza debilitante do sistema imune.

Não houve qualquer distribuição preferencial no que diz respeito a sexo e idade, nestes casos estudados. O caso de menor idade corresponde a uma criança de 8 meses e o mais idoso um individuo de 50 anos.

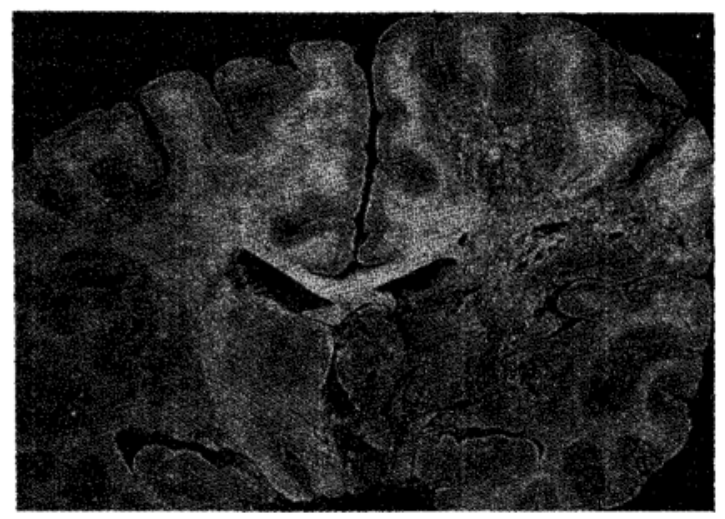

Fig. 5 - Superficie de corte do cérebro de um dos casos graves de toxoplasmose, mostrando lesão necrotizante com fragmentação tecidual, localizada no hemisfério direito.

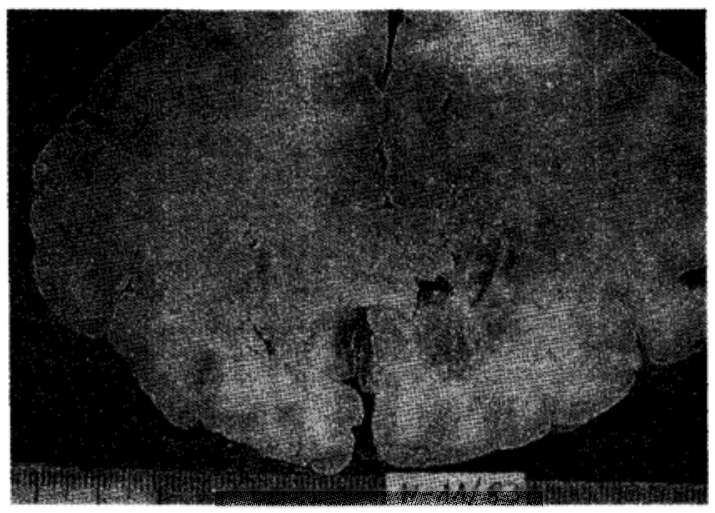

Fig. 6 -Desintegração tecidual localizada no lobo frontal direito simulando abscesso cerebral, em um caso grave de toxoplasmose. 
Queiroz AC, Nascimento CMPC, Ramos EAG. Toxoplasmose do sistema nervoso central. Correlação clinicopatológica em 7 casos de autópsia. Revista da Sociedade Brasileira de Medicina Tropical 20: 175-180, Jul-Set, 1987.

\section{DISCUSSÃO}

Do ponto de vista anatomopatológico, as lesões encefálicas aqui observadas foram semelhantes àquelas descritas em outros trabalhos ${ }^{13} 17$, com quadro de meningoencefalite multifocal necrotizante e parasitișmo de intensidade variável nos tecidos. Apresentação mais rara foi vista em 2 casos, com grande destruição do tecido nervoso em áreas que simularam abscessos cerebrais. O comprometimento de plexo coróide na toxoplasmose não tem sido referido na literatura, mesmo naqueles trabalhos que se preocupam em estudar a agressão do epêndima nesta doença ${ }^{17}$. A ocorrência de acometimento de plexo coróide, em todos os 4 casos em que esta estrutura foi examinada, pode sugerir um papel importante desta lesão na disseminação da doença no sistema nervoso central, a exemplo do que tem sido comentado no estudo de outras doenças infecciosas encefálicas, como a tuberculose, doença de Chagas e tripanosomíase africana ${ }^{5} 18$.

O trabalho demonstra a existência de toxoplasmose em nosso meio, considerada doença rara em várias regiōes 16 , tendo ocorrido no Hospital Prof. Edgard Santos num percentual detectável de 0,24\%, correspondendo a 6 casos da doença em 2.449 necrópsias realizadas. Devemos chamar atenção para o contraste entre estas cifras da doença e os percentuais de toxoplasmose infecção, variáveis entre $36 \%$ e $61 \%$ de acordo com os vários trabalhos sobre o assunto ${ }^{9} 11$, sendo esta última situação uma condição benigna sem expressão clínica significativa, enquanto a toxoplasmose doença representa condição de gravidade variável por vezes fatal como foram os casos aqui apresentados. O trabalho mostra também o problema da dificuldade de diagnóstico clínico da doença, conforme já tem sido chamada atenção por outros autores 1115 16. Em nenhum dos nossos casos houve sequer suspeita clínica da doença, não tenđo sido realizado qualquer exame complementar específico que pudesse comprovar a doença. Isto demonstra a falta de maior divulgação desta afecção, particularmente em casos de evolução mais grave e fatal. Vale ressaltar que mesmo em centros maiores, que contam com condições mais accessiveis para o diagnóstico laboratorial, a toxoplasmose não é facilmente diagnosticada $^{\mathbf{1 4}}$, devido ao aspecto inespecifico e proteiforme das suas manifestações clínicas, particularmente no que se refere ao envolvimento do sistema nervoso central. Dai, o maior número de casos serem diagnosticados após exame de autópsias. As coisas se tornam mais dificeis ainda, quando sabemos que, embora mais raramente, a toxoplasmose do sistema nervoso central pode-se apresentar com formas anatomoclínicas menos comuns, como esteve presente em dois dos nossos casos, quando os pacientes tiveram manifestações clínicas de lesão expansiva do SNC e, que mesmo no exame macroscópico do encéfalo, tiveram o diagnóstico de abscessos cerebrais. Esta experiência, também vivida por outros autores ${ }^{4} 16$, confirma a dificuldade em diagnosticar a toxoplasmose doença.

Tendo em vista todos estes fatos e estas dificuldades, torna-se imperativo, diante de um paciente febril com manifestações de lesão do $\mathrm{SNC}$, que se pense no diagnóstico de toxoplasmose, desde que a doença não tem uma manifestação clínica específica e, principalmente, porque os métodos laboratoriais desta doença são accessiveis, sensiveis e especificos para o seu diagnóstico, e principalmente porque o tratamento assim orientado pode mostrar-se eficaz no controle da doença $^{12} 1314$.

\section{SUMMARY}

This paper reports the pathological findings in seven cases of toxoplasmosis of the central nervous system. At post mortem examination a pattern of necrotizing multifocal meningoencephalitis was seen.

There is a great concern about the difficulty in the clinical diagnosis of the disease when it involves the central nervous system, particularly in relation to bizarre presentations. Two of our cases had a clinical and pathological pattern resembling cerebral abscesses.

The high frequency of the involvement of the choroid plexus suggests an important role for this structure in the dissemination of the infection in the central nervous system.

Key words: Toxoplasma gondii. Toxoplasmosis. Toxoplasmic encephalitis. Clinicopathological correlation.

\section{REFERÊNCIAS BIBLIOGRÁFICAS}

1. Araújo SA. Toxoplasmose na Bahia: Resultados preliminares do levantamento sorológico entre recrutas do exército no estado da Bahia-Brasil. In: Resumos do Congresso da Sociedade Brasileira de Medicina Tropical. Temas livres. Campinas, 1974.

2. Barbier D, Ancelle T, Martin-Bouyer G. Seroepidemiological survey of toxoplasmosis in la Guadeloupe French West Indies. American Journal of Tropical Medicine and Hygiene 32: 935-942, 1983.

3. Baruzzi RG. Contribuição para o estudo epidemiológico da toxoplasmose. Levantamento sorológico em índios do alto Xingu, Brasil Central. Revista do Instituto Adolfo Lutz 29/30: 105-139, 1969/70.

4. Bobowski S, Reed NC. Toxoplasmosis in an adult presenting as an space occupying lesion. Archives of Pathology 65: 460-464, 1958.

5. Cendon Filha SP, Queiroz AC. O envolvimento do plexo coróide e epêndima na tuberculose. Sua importância na disseminação da doença no Sistema Nervoso Central. In: 
Queiroz AC, Nascimento CMPC, Ramos EAG. Toxoplasmose do sistema nervoso central. Correlaçào clinicopatológica em 7 casos de autópsia. Revista da Sociedade Brasileira de Medicina Tropical 20: 175-180, Jul-Set, 1987.

Anais do XVI Congresso Brasileiro de Patologia. Ribeirão Preto, SP, 1985.

6. Feldman MA, Miller LT. Serological study of toxoplasmosis prevalence. American Journal of Hygiene 64:320-335, 1956.

7. Feldman MA. A nation wide serum survey of United States military recruits toxoplasma antibodies. American Journal of Epidemiology 81: 385-391, 1962.

8. Frenkel JK, Ruiz A. Epidemicity of toxoplasmosis in Costa Rica. American Journal of Epidemiology 113: 254-269, 1981.

9. Frenkel JK. Toxoplasmosis: mechanisms of infection, laboratory, diagnosis and management. Current Topics in Pathology 54: 28-75, 1971.

10. Frenkel JK, Nelson BM, Arias-Stella J. Immunosuppresion and toxoplasmic encephalitis. Clinical and experimental aspects. Human Pathology 6:97-111, 1975.

11. Galvão MM, Chocair PR, Ianhez LE, Sabbaga E. Manifestações neuropsíquicas da toxoplasmose em pacientes de alo-enxerto renal. Revista do Hospital das Clínicas da Faculdade de Medicina de São Paulo 35: 48$51,1980$.

12. Gleason TM, Hamlin WB. Disseminated toxoplasmosis in the compromised host. Archives of Internal Medicine 134:1059-1062, 1975.

13. Hussey HM. Toxoplasmosis of the central nervous system. American Journal of Medical Association. 232:743, 1975 .
14. Hyakutake S. Levantamento sorológico para toxoplasmose na região do baixo-médio São Francisco, estado da Bahia-Brasil. Revista do Instituto Adolfo Lutz 40:1-7, 1980.

15. Markus MB. Toxoplasmosis and neurological disease. The Lancet 1:565, 1978.

16. Masson R, Tiere D, Lahneche B, Cordot C, Berger F, Reval L. Toxoplasmose encephalique pseudo-tumorale au cours d'une hemopathie. Deux observations. La Nouvelle Presse Médicale 4:2499-2502, 1975.

17. Merencio JPC, Lopes VGS, Menezes DMF. Lesões encefálicas da toxoplasmose congênita. Jornal de Pediatria 40:363-369, 1979.

18. Queiroz AC, Castro Filho BG. Estudo do plexo coróide na infecção chagásica experimental em camundongos. Acta Medica Portuguesa 6:181-182, 1985.

19. Ricciardi IO, Sabroza PC, Sandoval ED, Mayrink W. Seroepidemiological study on the prevalence of human toxoplasmosis in Brazil. Revista de Microbiologia (São Paulo) 9:181-187, 1978.

20. Wallace GO. Serologic and epidemiologic observations on toxoplasmosis on Pacific islands and the influence of ethnic group. American Journal of Tropical Medicine and Hygiene 25:42-52, 1976.

21. Walls KW, Kagan LG, Turnera A. Studies on the prevalence of antibodies to Toxoplasma gondii. I. US military recruits American Journal of Epidemiology 85:87-92, 1967. 